\title{
EDUARDO NEVES, NOSSO ETERNO MESTRE
}

\author{
Ivano G. R. Gutz \\ Instituto de Química, Universidade de São Paulo, Av. Prof. Lineu Prestes, 748, 05508-000 São Paulo - SP, Brasil
}

Recebido em 28/7/06

\begin{abstract}
IN MEMORIAM: EDUARDO NEVES, OUR UNFORGETTABLE MASTER. Eduardo Fausto de Almeida Neves, Professor Emeritus of the Universidade Federal de São Carlos and formerly Full Professor at the Instituto de Química - Universidade de São Paulo (USP), São Paulo, Brazil, was born in November 7, 1933 in Pedra Azul, MG, and deceased in July 2, 2006 in São Carlos, SP. He graduated under supervision of Professor Paschoal Senise, pioneer of Analytical Chemistry at USP, and developed his post-doctoral work at Caltech, USA, with Professor Fred Anson. His brilliant career as teacher, scientist, supervisor and mentor resulted in a prolific science school in Analytical Chemistry, with some sixty PhDs and masters supervised by him, amplified to over four hundred in the 2nd to 4th generations (still growing), spread throughout the country and nucleating new research groups. The contents of a hundred papers reflect Prof. Eduardo's wide range of scientific interests. Passionate inclination for creative intellectual activity, rooted in profound knowledge of all branches of Chemistry, broadminded thinking, sound experimentation, generous scientific cooperation and true friendship - that's why friends, colleagues and students referred to him as "master" or "my guru".
\end{abstract}

Keywords: in memoriam; Electroanalytical Chemistry; Analytical Chemistry.

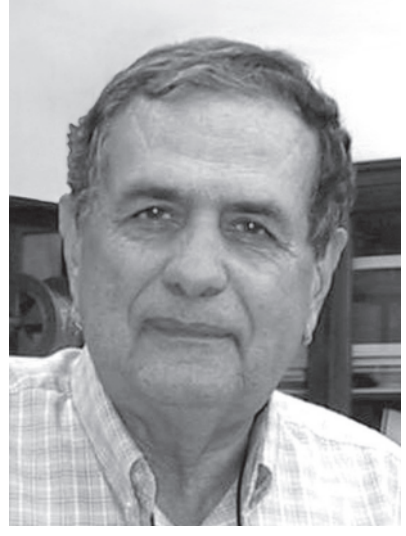

No dia 02 de julho de 2006, a ciência brasileira perdeu um dos seus mais importantes químicos analíticos, o Professor Emérito Eduardo F. A. Neves. Proeminente cientista, profuso manancial de idéias e genuíno Patrono da Química Eletroanalítica no Brasil, fez escola por quatro décadas, formando mestres e doutores em química analítica que se espalharam pelo Estado de São Paulo e pelo país e que continuaram a tratá-lo como mestre (ou guru) por toda vida. A compreensão da química como um todo, a preponderância da atividade intelectual criativa respaldada em intensa experimentação conduzida com técnicas acessíveis e de custo compatível com a situação do país, preferencialmente eletroanalíticas, a exigência de originalidade e excelência nas teses e publicações, o trabalho intenso, a cooperação e a amizade são alguns dos valores da escola implantada por Eduardo Neves, que teve os Professores Paschoal Senise e Heinrich Rheinboldt como ilustres ancestrais científicos na Universidade de São Paulo ${ }^{1}$. Neste artigo, procurar-se-á reverenciar sua memória e deixar entrever, aos que não tiveram o privilégio de conhecê-lo, a sua magnitude como humanista e cientista.

Nascido em Pedra Azul, MG, em 7 de novembro de 1933, Eduardo Fausto de Almeida Neves entrou em contato com a química muito cedo, no pequeno laboratório que seu pai mantinha junto ao consultório odontológico, nas aulas de ciências do ginásio (dadas por entusiástico engenheiro) e no laboratório fotográfico que ele se montou. Em 1950, o jovem Eduardo se dirige a Belo Horizonte, para cursar o Científico no Instituto Padre Machado, dirigido pelo brilhante acadêmico, Prof. Otto Lara Rezende.

\footnotetext{
*e-mail: gutz@iq.usp.br
}

Decidido a estudar Química, seguiu para São Paulo em 1953 e ingressou no curso de Química da Faculdade de Filosofia, Ciências e Letras da USP em 1954. Nesse curso extremamente rigoroso, organizado a partir de 1934 em moldes germânicos pelos Profs. Heinrich Rheinboldt e seu então assistente Heinrich Hauptmann, estudou e aprendeu muito com esses pioneiros e com os primeiros doutores formados por Rheinboldt, entre os quais, Simão Mathias, Paschoal Senise, Ernesto Giesbrecht e Geraldo Vicentini, assim como com outros professores. Destacou-se muito, sendo lendário o fato de nunca errar uma análise qualitativa. Dedicava as férias à iniciação científica, estagiando nos laboratórios. Dos 30 ingressantes de sua turma, além de Eduardo (centro direita na foto), só Franco Levi, Divo Sanioto (centro), José Roberto Giglio (centro esquerda) e Karola Zimber se graduaram em 1957. Obteve os diplomas de Bacharel

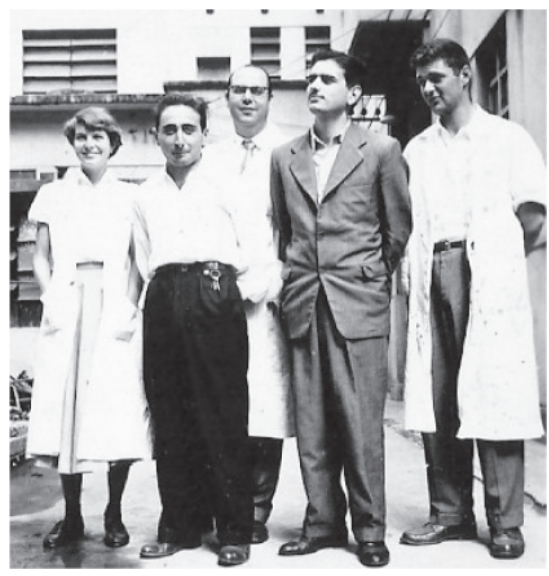
com Atribuições Tecnológicas e o de Licenciatura em Química. No mesmo ano de 1957, começou a lecionar no curso noturno do Colégio Oswaldo Cruz.

Em 1958, iniciou seu doutorado sob orientação do Prof. Paschoal Senise, o $1^{\circ}$ discípulo de Rheinboldt a abraçar a Química Analítica. A essa altura, Senise já havia retornado de pós-doutoramentos com os Profs. P. W. West e Paul Delahay (autor de "New Instrumental Methods in Electrochemistry"). Em suas pesquisas, Neves estudou sistematicamente as interações de pseudo-haletos como o azoteto com boa parte dos metais da tabela periódica, enfocando a estabilização de estados de oxidação menos usuais e os equilíbrios de coordenação, recorrendo amplamente à polarografia e à potenciometria, 
mas também à espectrofotometria. Seu especial talento para a pesquisa foi logo notado e, já em 1959, foi contratado pela FFCL-USP, inicialmente como Auxiliar de Ensino em tempo parcial. A partir de 1961, passou a acumular atividades de pesquisa e ensino como Instrutor em tempo integral do Departamento de Química.

Eduardo acompanhou a integração, coordenada pelo Prof. Senise (hoje, Prof. Emérito da USP), de todos os docentes, disciplinas e pesquisas em química, e grande parte das de bioquímica, dispersas pelas diferentes unidades da Universidade, no recém criado Instituto de Química da USP. Sua tese "Estudos sobre a reação entre íons azoteto e cátions metálicos" foi a primeira a ser defendida nas novas instalações do IQ-USP, em 1966. Dela derivaram 7 publicações.

Já como Prof. Assistente Doutor e incentivado pelo Prof. Pawel Krumholz, Neves estreou como orientador em 1968, ano em que também formulou e credenciou a $1^{\mathrm{a}}$ disciplina de pós-graduação do IQ-USP, "Alguns Aspectos da Química Eletroanalítica”. Essa disciplina teórico-experimental foi ministrada por Neves por duas décadas no IQ-USP, com progressiva colaboração de seus seguidores que, a partir dos anos 90, a assumiram e oferecem até hoje, após graduais atualizações de conteúdo e retoques no título. Cursada por centenas de pós-graduandos, auxiliou na irradiação da química eletroanalítica pelo país.

Tendo por objetivo principal quantificar a adsorção eletroquímica dos complexos que vinha estudando, Neves seguiu, em 1971, para o California Institute of Technology, onde o conceituado Prof. Fred Anson e colaboradores haviam inventado, poucos anos antes, a cronocoulometria. Ao longo dos 2 anos de pós-doutorado, entre outros estudos, observou novos e interessantes fenômenos de adsorção induzida de complexos lábeis de "metais brancos", que interpretou na sua tese de Livre Docência "Participação de ânions na adsorção de complexos de 2-2'-dipiridila sobre eletrodo de mercúrio", fazendo analogias com a extração por solventes. A defesa, realizada com brilhantismo em 1973, lhe assegurou a posição de Prof. Livre-Docente no IQ-USP. A interação com o Caltech se estendeu no âmbito do programa CNPq/NAS com a vinda do Prof. Anson ao Brasil e novo estágio do Prof. Eduardo, acompanhado do autor deste artigo, no Caltech, em 1980, para acelerar estudos cronocoulométricos de adsorção com a instrumentação computadorizada de Anson por interfaceamento de eletrodo automático de mercúrio desenvolvido no IQ-USP.

Colaborando para amenizar a falta de docentes altamente qualificados em química analítica nas universidades públicas do interior do Estado de São Paulo, o Prof. Eduardo acumulou incumbências de docência em um dos dias da semana na Faculdade de Filosofia, Ciências e Letras de Ribeirão Preto - USP no início da década de 1970, posteriormente, na FFCL de Araraquara (atual IQ-UNESP) e, no final da década de 1980, no Departamento de Química da Universidade Federal de São Carlos, sempre dentro das normas da USP. Também ministrou cursos de férias em Química Analítica ou Eletroanalítica em diversas universidades - de Natal a Santa Maria.

O Prof Eduardo Neves orientou, no IQ-USP, as teses de doutorado de Douglas W. Franco (defendida e aprovada em 1972), Elizabeth de Oliveira (1974), Roberto Tokoro (1977), Ivano G. R. Gutz (1978), Gilberto Chierice (1978), Morena P. Peters (1980), Zacheu L. Santos (1980), Ruth G. Tavares (1981), Jose F. Andrade (1982), Maria E. V. Suarez (1983), Wagner Polito (1983), Thais V. Silva (1984), Nina Coichev (1984), Orlando Fatibello Fo. (1985), Luiz H. Mazo (1985), Luis A. Azevedo (1986), Milton Capelato (1988), Tânia Tavares (1990, co-orientador, Dieter Klockow), Dilson R. Zanette (1992), Maura V. Rossi (1992), Arnaldo Bona (1994), Márcia Guekezian (1996); na UFSCar, Eduardo orientou José A. Santos (1995), Neila M. Cassiano (1998), Rosa L. G. N. P. da Silva (1999), Edemar Benedetti Fo. (2000), Ruth Andrade (2003), Debora C. de
Souza (2004), Marcilene Ferrari Bariquello (2005), Andréa Boldarini Couto (2005). Entre as teses co-orientadas figuram as de Silvia L. Agostinho (1975, orientador: Ivo Jordan), Joachim Gebert (1988, orientador: Dieter Klockow) e Horácio D. Moya (1998, orientador: Nina Coichev) e colaborou no desenvolvimento de incontáveis outras teses. No primeiro semestre de 2006, três estudantes de doutorado trabalhavam sob orientação de Eduardo Neves na UFSCar.

A relação de dissertações de mestrado orientadas por Neves reúne, no IQ-USP, Roberto Tokoro (1974), Luis A. Azevedo (1976), Nelson C. Milcken (1977), Luis H. Mazo (1978), Vera L. Leitão (1980), João O. Tognolli (1980), Lúcio Angnes (1981), Márcio Augelli (1981), Celia de Oliveira (1982), Maura V. Rossi (1986), Josely K. Oliveira (1986), Evaldo de Oliveira (1986), Jose J. Pecchioni (1988), Márcia Guekezian (1992), Horácio D. Moya (1993), Hilda M. S. Leite (1998); na UFSCar, Joseane Bülow (1994), Luciana M. Saran (1997), Edemar Benedetti Filho. (1997), Maria C. T. Diniz (1998), Débora C. Souza (2000), Andrea P. Oliveira (2004), Elen Sartori (2005). Neves também co-orientou as dissertações de Maria F. N. Campos (1991, orientador: Milton D. Capelato), Cláudia M. M. Inga (1997, orientador: Ivano G. R. Gutz), Antonio R. Fiorucci (1999, orientador: Éder T. G. Cavalheiro), Cláudia Bernal (1999, orientador: Éder T. G. Cavalheiro), Elisângela C. Lima (2000, orientador: Antônio Mozeto). Eduardo Neves não teve tempo de concluir a orientação de um mestrando adicional na UFSCar.

Vários mestres e doutores preparados pela escola do Prof. Eduardo Neves foram admitidos pelo próprio Instituto de Química, sendo que em 2002 ainda respondiam por cerca de metade do quadro ativo da área de Química Analítica do IQ-USP (os Profs. Roberto Tokoro e de Maria Encarnación V. Suarez Iha se aposentaram posteriormente).

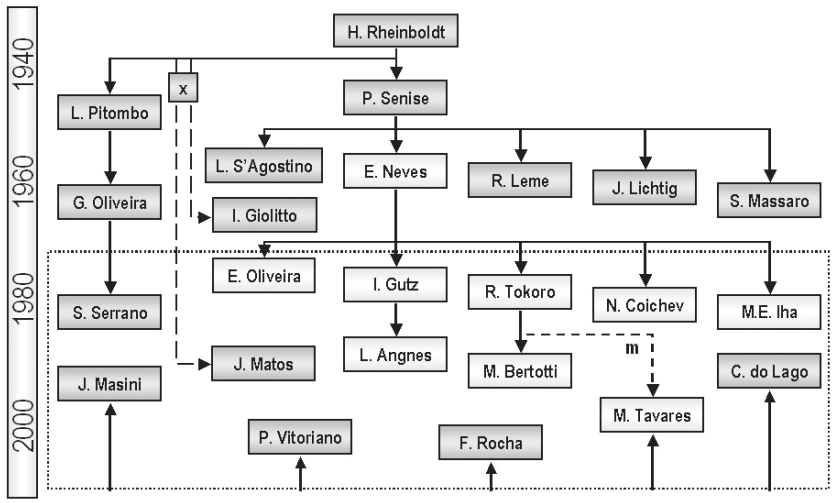

Genealogia acadêmica da Escola de Neves na área de concentração de Química Analítica do Instituto de Química da USP, São Paulo. A moldura pontilhada enquadra os docentes ativos (não aposentados) no ano de 2002. Por razões de clareza, foram omitidos alguns ex-docentes. A letra $\boldsymbol{m}$ indica orientação de mestrado. Setas ascendentes apontam para docentes que se doutoraram fora do IQ-USP. A letra X representa descendentes de Rheinboldt de outras áreas

Todavia, um número até maior de pós-graduados orientados por Neves conquistou posições no "tetrâmero de cursos de química" no centro do Estado de São Paulo: Douglas W. Franco, Gilberto O. Chierice, Luis H. Mazo e Wagner L. Polito no Instituto de Química de São Carlos, da USP em São Carlos (IQSC-USP), Orlando Fatibello-Filho e Milton D. Capelato no Departamento de Química da Universidade de São Carlos (UFSCar), João O. Tognolli no Instituto de Química da UNESP (IQ-UNESP), e José F. de Andrade no Departamento de Química do campus da USP em Ribeirão Preto (DQ-FFCLRP-USP). A maioria dos demais discípulos se distribuiu 
pelas universidades federais dispersas pelo país, mas alguns se estabeleceram em instituições privadas em São Paulo; todos ajudaram a elevar o nível de ensino da química analítica nestas instituições e a introduzir e aumentar o nível das atividades de pesquisa, independentemente das adversas condições locais. Muitos dos egressos da escola de química analítica de Eduardo Neves se dedicaram, também, à atividade formadora e já orientaram cerca de quatro centenas de teses e dissertações de mestrado; é válido supor que a segunda geração, ainda jovem, ultrapasse rapidamente esse número - se já não o fez - e é certo que já há numerosos pós-graduados descendentes de terceira geração forjando a quarta geração, ainda sob a égide e influxos do eterno mestre.

Retrocedendo três décadas, na época em que se preparava para galgar a posição de Professor Adjunto no IQ-USP, Eduardo uniu seus esforços aos do Prof. Tibor Rabóczkay na gênese do Simpósio Brasileiro de Eletroquímica e Eletroanalítica, realizado pela primeira vez em outubro de 1978 e instituído com periodicidade bienal. O $2^{\circ}$, o $5^{\circ}$ e o $6^{\circ}$ SIBEEs também tiveram lugar no IQ-USP. As circunstâncias, a marcante trajetória de sucesso do Simpósio e seus reflexos na difusão e consolidação das pesquisas nesses campos foram avaliados em recente publicação dos Profs. Luis A. Avaca e Roberto Tokoro ${ }^{2}$.

Eduardo conquistou seu primeiro título de Professor Titular em concurso público realizado no IQ-USP em 1983. Em seu memorial, além de apreciação das inúmeras linhas de pesquisa, se dá a conhecer através de fatos, idéias e pontos de vista. Esse estilo de memorial foi muito apreciado pela banca. Nele estão sumarizadas algumas das lições de vida que o erudito "mestre" metabolizou e procurava passar aos jovens discípulos da sua escola no convívio diário. A título de exemplo, segue transcrição de parte dos seus comentários sobre a atividade criativa em ciência:

\begin{abstract}
"Sem dúvida, idéias geram idéias. Mas cuidado! Pode parecer paradoxal, mas excesso de estudo inibe a imaginação criadora.... Idéias surgem freqüentemente em debates científicos, daí a importância de seminários e dos congressos de ciências em que ouvintes atentos podem encontrar soluções inspiradas momentaneamente para seus problemas de pesquisa. Melhor ainda é o debate científico informal e diário. Gosto muito de sair com meus alunos de pós-graduação para almoçar fora do Instituto, percorrendo 2 quilômetros a pé. Muitos problemas de pesquisa foram discutidos nessas circunstâncias, ou subindo o pico do Jaraguá, ou na mesa do chope em moderadas celebrações... Quem lida com ciência não pode separar totalmente o trabalho do lazer. Isso não é obsessão pelo trabalho mas amor à Arte, a espera da criatividade. A mente inconsciente, que gera idéias e é fonte de inspiração, não escolhe hora para liberar seu refinado produto. $O$ subconsciente precisa ser estimulado e abastecido... Basta manter uma discreta atitude de alerta para as idéias que surgem em rápidos devaneios e que devem ser captadas para, às vezes, não se perderem para sempre."
\end{abstract}

Nos anos 80, o Prof. Eduardo manteve intercâmbio com o Prof. D. Beterridge na Universidade de Swansea (Reino Unido) centrado no uso de microcomputadores em instrumentação analítica. Em seguida, estabeleceu duradoura cooperação com o Prof. D. Klockow, da Universidade de Dortmund e do ISAS (Alemanha) em temas ligados à química analítica ambiental. Idéias de pesquisa do Prof. Eduardo prosperaram também em outros laboratórios do exterior, por exemplo, nos do Prof. Rudi van Eldik (Univ.Witten/Herdecke, Alemanha). Por toda a vida acadêmica o "mestre" semeou idéias, discutiu trabalhos de pesquisa e auxiliou os que enfrentavam problemas científicos aparentemente insolúveis, fossem estudantes, colegas ou orientadores, da sala de aula à conferência plenária, da banca- da de laboratório à defesa de tese, da conversa de corredor à confraternização, da academia à indústria. Manteve colaborações com vários discípulos e participou de muitos projetos, inclusive para captar recursos visando a implantação dos laboratórios destes.

Institucionalmente, Neves atuou decisivamente nos colegiados e em muitas comissões, em especial, na de Pós-graduação do IQ-USP, onde "catalisou" a ampliação do quadro de orientadores e pósgraduandos em química analítica e o aparelhamento dos laboratórios, assegurando a manutenção do conceito máximo nas avaliações da CAPES. Externamente, atuou no Comitê de Química do CNPq e na CAPES, entre outros. De 1987 a 1989, Neves exerceu de forma hábil e discreta, a chefia do Departamento de Química Fundamental do IQ-USP, então com perto de 80 docentes. Além de cumprir as atribuições regimentais, reduziu atritos remanejando para novos laboratórios docentes que não estavam bem integrados em certos grupos, incentivou colega já desmotivado a se aposentar e solucionou eventuais conflitos entre alunos e docentes antes que adquirissem vulto e fossem reverberados. Próximo ao final da gestão na chefia, solicitou merecida aposentadoria. Para atenuar a enorme lacuna que deixou, completou a orientação dos seus pós-graduandos e durante anos manteve as colaborações com discípulas-docentes no IQ-USP, reduzindo-as na proporção do crescimento da independência destas.

Ao invés de moderar a atividade profissional após a aposentadoria, aceitou prontamente o convite do Departamento de Química da UFSCar para ingressar em seus quadros e, em 1991, venceu concurso de Professor Titular aberto nessa universidade. Acumulou, pois, a colaboração remanescente com o IQ-USP com novo ciclo de intensa atividade de docência, orientação, pesquisa e atuação institucional. Logo após a sua integração na UFSCar, organizou a pós-graduação em química analítica instituindo a um só tempo os programas de mestrado e doutorado, contrariando resistências de outras áreas do Departamento que consideravam precoce a abertura do doutorado. As dezenas de mestres e doutores formados e a excelente avaliação pela CAPES, comprovam o acerto da iniciativa. Entre 1993 e 1995 exerceu a função de chefe do Departamento de Química da UFSCar. Neste início de milênio, atingiu com tal dinamismo a aposentadoria compulsória dos heptagenários, que foi convidado a prosseguir atuando na UFSCar como Professor Voluntário e, em seguida, como Professor Emérito.

A produção científica do Prof. Eduardo encontra-se registrada em uma centena de trabalhos publicados majoritariamente em periódicos internacionais de primeira linha. Meia centena de contribuições adicionais foi publicada em forma completa nos Anais dos primeiros 7 SIBEEs. Sua obra é pautada pela qualidade e pela surpreendente gama de linhas e temas pesquisados, entre os quais: numerosos estudos fundamentais de equilíbrios de complexos metálicos, inclusive envolvendo espécies mistas e polinucleares; estudos de processos de difusão e de adsorção induzida de complexos; propostas de instrumentação analítica e programas computacionais; desenvolvimento de ampla gama de métodos eletroanalíticos, espectrofotométricos, por vezes catalíticos, eventualmente em fluxo; desenvolvimento de acumuladores baseados em sais solúveis de chumbo; eletro-síntese orgânica; elucidação de mecanismo de resposta de eletrodo íon seletivo de fase sólida; novas modalidades e aplicações de titulações clássicas; estudos de extração por solventes; estudos de cinética química, com propostas de mecanismos; estudos de interesse ambiental envolvendo espécies como $\mathrm{SO}_{2}$, óxidos de nitrogênio, ácidos húmicos, $\mathrm{SF}_{6}$ e seus produtos de degradação; artigos didáticos; revisões e importantes resenhas sobre a situação da química analítica no país. Destacou-se internacionalmente em pesquisas envolvendo o íon azoteto, tendo sido convidado pela American Chemical Society para apresentar 5 de seus trabalhos sobre este pseudo-haleto na $124^{\circ}$ Congresso Anual da ACS em 1982. 
Mas as incessantes atividades de pesquisa do Prof. Eduardo ao longo das décadas não se restringiram ao ambiente acadêmico. Para aquilatar a abrangência da sua atuação na área aplicada ou tecnológica, servem de exemplo: a) Desenvolvimento de importante projeto de aproveitamento das águas-mães das salinas, com pesquisadores da Universidade Federal do Rio Grande do Norte; b) Coordenação de amplo convênio multidisciplinar plurianual com o antigo $\mathrm{CPqD}$ da Telebrás, enfocando aperfeiçoamento de baterias estacionárias para centrais telefônicas que, entre outros resultados, gerou protótipo absorvido pelos meios produtivos; c) Consultoria na COPEL (Companhia Energética do Paraná) em problemas de corrosão de geradores, contaminantes em águas e dielétricos gasosos, conduzindo a soluções que proporcionam economia de milhões dólares ao longo dos anos; d) Recentemente patenteou processo de remoção de íons $\mathrm{Cu}$ (II) de aguardente de cana de açúcar a partir de troca iônica com carbonatos de cálcio ou magnésio.

Nada mais natural, pois, que o sistema de Bolsas de Produtividade do CNPq o tenha classificado, durante décadas, no nível máximo e que ocupasse posição de Membro Titular da Academia Brasileira de Ciências e da Academia de Ciências do Estado de São Paulo. Entre as honrarias e homenagens que recebeu em vida figuram: um Simpósio de Química Analítica que lhe foi dedicado pela Associação Brasileira de Química durante o XXIX Congresso Brasileiro de Química (São Paulo, 1989), a Medalha Simão Matias, conferida pela Sociedade Brasileira de Química na 24 Reunião Anual (Poços de Caldas, 2001), homenagem no XIII Simpósio Brasileiro de Eletroquímica e Eletroanalítica (Araraquara, 2002), ocasião em que foi reconhecido como Patrono da Química Eletroanalítica no Brasil, homenagem na 54 ${ }^{\text {th }}$ Annual Meeting of the International Society of Electrochemistry (São Pedro, 2003), homenagem no XIV Encontro Regional da SBQ (São Carlos, 2003), Professor Emérito da Universidade Federal de São Carlos (São Carlos, 2005), homenagem no Encontro Nacional de Química Analítica (Niterói, 2005), publicada no Microchemical Journal ${ }^{3}$ e a Medalha Prof. Waldemar Safiotti, entregue durante a XV ERQ/SBQ (Ribeirão Preto, 2005).

Nestas linhas finais há que citar, ao menos, alguns dos atributos pessoais do Prof. Eduardo: sua retidão de caráter, suas posições políti- cas determinadas, seu estilo discreto de vida, despojado de bens materiais e confortos supérfluos, seu amor pela esposa e filhos, sua afeição pelos pais e pela distante terra natal, visitados uma ou mais vezes ao ano.

Sua proeminência como pessoa e cientista se agigantava à medida que se alongava o privilégio do convívio quase familiar ou de relação mestre-discípulo, dos que o tiveram como orientador, amigo ou colega. Mesmo os que o encontravam apenas ocasionalmente em eventos científicos, logo se davam conta de algumas das suas qualidades. Ao saber do falecimento do Prof. Eduardo, assim se manifestou um químico analítico do Rio de Janeiro:

"O Eduardo era daquelas pessoas tranqüilas, acima das emoções imediatas, de grande sabedoria. Sem polemizar, deixava claros seus pontos de vista, e sabia ouvir. Era sempre muito interessante estar numa roda onde ele se encontrava, pois se tinha a certeza de aprender alguma coisa a mais, de modo delicado e carinhoso."

Em novembro de 2003, por ocasião do seu septuagésimo aniversário, o mestre concluiu com as seguintes palavras a magnífica reflexão que escreveu sobre o transcurso da sua vida:

“... Vislumbro agora a luz do sol poente e o lusco-fusco que logo se sucederá. Para dar espaço à noite escura que um dia virá... E anunciar o tempo de partir e reencontrar, na imensidão do cosmo, o caminho interrompido."

Nossa gratidão ao eterno mestre, pelo exemplo e por tantos ensinamentos deixados durante sua permanência conosco.

\section{REFERÊNCIAS}

1. Senise, P.; Origem do Instituto de Química da USP - Reminescências e Comentários; Instituto de Química: São Paulo, 2006.

2. Avaca, L. A.; Tokoro, R.; Quim. Nova 2002, 25(Supl. 1), 25.

3. Ferreira, S. L. C.; Santelli, R. E.; Aquino Neto, F. R.; Nóbrega, J. A.; Cassella, R. J.; Microchem. J. 2006, 82, 123. 